\title{
Role of earth-abundant selenium in different types of solar cells
}

\author{
Tania Dey ${ }^{1}$
}

\begin{abstract}
This mini review covers a brief overview of three generations of solar cells, definition of major photovoltaic (PV) parameters, mechanisms, advantages and limitations of different types of solar cells such as multijunction, thin film, quantum dot, dye sensitized and perovskite solar cells, and what role the earth abundant selenium can play in each type of solar cells, followed by a comparative study of the benefits and challenges that selenium can offer in terms of PV properties, as well as the major players and cost analysis in this arena. As far as PV properties are concerned, $\operatorname{BaZr}\left(\mathrm{S}_{0.6} \mathrm{Se}_{0.4}\right)_{3}$ distorted chalcogenide perovskite solar cell can possibly lead the future, the next best ones being AlGaInP multijunction solar cell with Se emitter dopant and Se electrolyte additive in $\mathrm{Zn}-\mathrm{Cu}$-In-Se QD-sensitized solar cell. Cost-wise perovskite cell holds a lot of promise, but the efficacy of selenium needs to be explored further.
\end{abstract}

K e y w or d s: solar cell, selenium, thin film, quantum dot, perovskite, dye sensitized

\section{Introduction}

Energy production has become a big challenge, as the global demand for energy is increasing day by day. Exploring sustainable energy resources such as solar and wind energy, devoid of the adverse environmental effects of fossil fuel combustion, is becoming a viable option. Judicious choice of energy materials is important for developing solar cells with high efficiency of solar energy to electric energy conversion. This review will discuss the mechanisms, pros and cons of different types of solar cells, namely multi-junction, thin film, quantum dot, dye sensitized and perovskite solar cells, and what role selenium can play in each type of solar cells, followed by a comparative study of the benefits, major players and cost analysis.

\section{Why Selenium}

The first solid-state solar cell, fabricated almost 140 years ago, was based on selenium. Selenium is an earth abundant semiconductor material and is transparent to light at photon energies below the band gap (reported band gap is $1.8-2.0 \mathrm{eV},[1])$. The high absorption coefficient (over $3 \times 10^{4} \mathrm{~cm}^{-1},[1]$ ) and mobility, the simplicity of a single element absorber, the low-temperature processing (below its melting point of $220^{\circ} \mathrm{C}$, [1]), and the intrinsic environmental stability makes selenium a lucrative component in cheap scalable solar cells.

\section{Three generations of solar cells}

The discovery of the photoelectric effect gave birth to the crystalline silicon cell that marked the beginning of photovoltaic (PV) industries. This microelectronics based first generation solar cell covers $80 \%$ of the world installed capacity today [2] and currently represents $90 \%$ of the market shares [2], in spite of its cost and efficiency limitations.

The second generation thin film based solar cells such as CdTe, copper indium gallium selenide (CIGS), and amorphous silicon were developed as a cheaper alternative to crystalline silicon cells. They provide better mechanical performance in flexible devices, but at the expense of lower efficiency.

The third generation solar cells (tandem, perovskite, dye-sensitized, organic etc.) account for a broad spectrum of emerging concepts, which has the potential to shape the future of the next generation photovoltaics.

\section{Important photovoltaic (PV) parameters}

The solar cell is operated over a wide range of voltages (V) and currents (I). By continuously increasing the applied voltage on an irradiated cell, from $\mathrm{V}=0$ (corresponds to short circuit current, $J_{s c}$ occurring at the beginning of the forward bias sweep) through the point of $I=0$ (corresponds to open circuit voltage, $V_{o c}$ ) to a very high value of $V$, it is possible to determine the maximum electrical power $\left(P_{\max }\right)$ which the cell can achieve and is given by $V_{\mathrm{m}} \times I_{\mathrm{m}}=P_{\max }$ in watts. The fill factor is given by $F F=P_{\max } /\left(J_{\mathrm{SC}} \times V_{\mathrm{OC}}\right)$.

A larger fill factor is desirable and corresponds to an $I-V$ sweep that is more square-like. The power conversion efficiency $(\eta)$, defined as the percentage of the solar power that is converted from absorbed light to electrical energy, is calculated from the following equation

\footnotetext{
${ }^{1}$ College of Engineering, Swansea University, Crymlyn Burrows, Swansea SA1 8EN, Wales, UK, taniadey@hotmail.com
} 
$\eta=\left(F F \times V_{\mathrm{OC}} \times J_{\mathrm{SC}}\right) / P_{\text {inp }}$ where $P_{\text {inp }}$ is the input light irradiance which illuminates the cell.

\section{Selenium in multijunction solar cell}

\subsection{Mechanism}

Multijunction solar cell is a type of tandem solar cell with multiple $\mathrm{p}-\mathrm{n}$ junctions made of different semiconductor materials. Multijunction solar cells are constructed by stacking semiconductors with varying bandgaps on top of one another, thereby allowing the cell to absorb differing wavelengths of solar radiation. The tunnel junction enables metal-to-metal electrical connectivity, which can also be achieved through an indium film processable at room temperature under low pressure [3]. Multijunction solar devices use a high-bandgap top cell to absorb high-energy photons while allowing the lower-energy photons to pass through. III-V compound semiconductors are good candidates for fabricating such multijunction solar cells, due to their capability to epitaxially grow with superior material quality and due to their bandgaps covering a wide spectral range. A typical multijunction cell uses two or more absorbing junctions and the theoretical maximum efficiency increases with the number of junctions.

\subsection{Advantages}

Triple-junction solar cells used for space applications can consist of indium gallium phosphide (InGaP), indium gallium arsenide (InGaAs) and germanium layers, fabricated using metal-organic chemical vapor deposition (MOCVD) with conversion efficiencies of over $37 \%$, while single-junction GaAs solar cells have achieved only $28 \%$ conversion efficiencies.

\subsection{Limitations}

Some of the major limiting factors of multijunction solar cell are the influence of window layer of the top cell, electrical properties of the emitter, and the band discontinuities formed at heterojunctions. In the case of the heterojunctions included in the multijunction solar cell, the impact of a high-band offset can be mitigated by increasing the doping level density thus favoring the tunneling effect [4]. These cells are much more expensive to produce than the less efficient thin solar films.

\subsection{Role and benefits of selenium}

NASA has reported a high-efficiency multi-junction solar cell comprising multiple semiconducting layers and an interface layer disposed between the multiple semiconducting layers. The interface layer is made from an interface bonding material that has a refractive index such that a ratio of a refractive index of each of the multiple semiconducting layers to the refractive index of the interface bonding material is less than or equal to 1.5 and selenium has proven to be an excellent choice in this case $[5]$.
The quaternary alloy AlGaInP offers the highest direct bandgap of any III-V material that is lattice- matched to GaAs. It is therefore a promising candidate for use in fivejunction and six-junction photovoltaic devices as well as for solar cells operated at high temperature. Scientists have shown that apart from the growth temperature during organometallic vapor phase epitaxy (OMVPE) and the cell thickness, choice of emitter dopant also plays a crucial role in AlGaInP multijunction cells [6]. By replacing silicon ( $\mathrm{Si}$ ) with selenium (Se) as the n-type dopant, they were able to achieve a notable increase in $V_{\text {oc }}$ as well as $J_{\mathrm{sc}}$ and $10.7 \%$ efficiency under a simulated AM1.5D spectrum (Tab. 1, Fig. 2).

\section{Selenium in thin film solar cell}

\subsection{Mechanism}

In a thin film solar cell, a doped semiconductor with excess free electron (n-type material) joins with a doped semiconductor with excess holes or vacancies (p-type material), with a layer in between known as junction. Even in the absence of light, a small number of electrons move across this junction from the n-type to the p-type semiconductor, producing a small voltage. In the presence of light, photons dislodge a large number of electrons, which flow across the junction to create a current output. For example, in CdTe thin film solar cell one electrode is made from a layer of carbon paste infused with copper and the other from tin oxide $\left(\mathrm{SnO}_{2}\right)$ or cadmium stannate $\left(\mathrm{Cd}_{2} \mathrm{SnO}_{4}\right)$. The semiconductor in this case is cadmium telluride (CdTe) which along with cadmium sulfide $(\mathrm{CdS})$, creates the $\mathrm{n}$-type and $\mathrm{p}$-type layers respectively, required for the $\mathrm{PV}$ cell to function.

\subsection{Advantages}

Thin film solar cells are easy to handle, more flexible than conventional solar cells, available as micron- scale thin wafer sheets, and much cheaper than traditional panels.

\subsection{Limitations}

There are health concerns associated with the use of cadmium in thin-film CdTe solar cells. Cadmium is a highly toxic substance that, like mercury, can accumulate in food chains [7]. On the other hand, the limited availability of indium and tellurium used in CdTe and CIGS thin film solar cells may lead to depletion of natural resources. The other disadvantages of thin film PV cells are less efficiency (20 to $30 \%$ of light converted into electricity), complex structure, need for careful handling, and unsuitability in astronomical devices. 


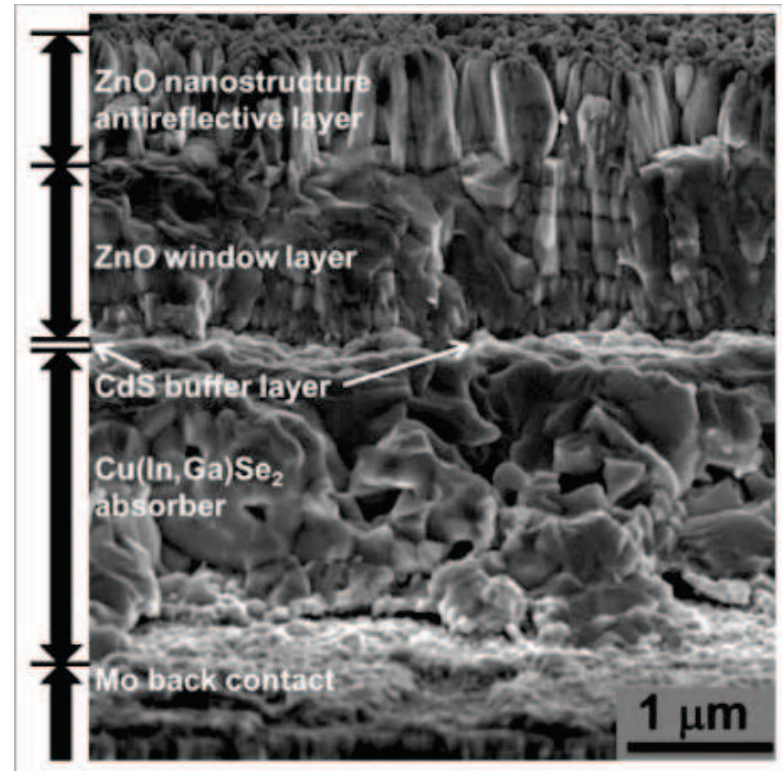

Fig. 1. Cross-sectional SEM image showing all layers in CIGS solar cell, reproduced from [13]

\subsection{Role and benefits of selenium}

A simplistic selenium thin film solar cell comprises of $4 \mu \mathrm{m}$ Se layer on $0.3 \mu \mathrm{m}$ ITO/glass with an ultra-thin tellurium layer in between to provide metallurgical bonding [8], with no anti-reflective coating eg sol-gel $\mathrm{SiO}_{2},[9]$. The historical selenium thin film solar cell utilizes n-type $\mathrm{TiO}_{2}$, deposited on $\mathrm{SnO}_{2}: F$ (FTO) coated glass and ptype Se followed by gold contact, [10]. This PV structure was further improvised in modern days by adding a reliable high work-function hole-selective layer $\mathrm{MoO}_{x}$, between the selenium and the gold back contact to reduce recombination, [1]. Deposition of Se thin film on a nanoporous $\mathrm{n}-\mathrm{TiO}_{2}$ film followed by a thin film of $\mathrm{p}$ $\mathrm{CuCNS}$ on the top has also been reported, where selenium thin film acts as a low band gap interlayer for injecting carriers into high band gap porous $\mathrm{n}-\mathrm{TiO}_{2}$ film [11].

Other Se containing thin film solar cells include hybrid organic-inorganic structure such as

n- $\mathrm{TiO}_{2} / \mathrm{Se} / \mathrm{P}_{3} \mathrm{HT} / \mathrm{PEDOT}: \mathrm{PSS} / \mathrm{Ag}$

where Se acts as a photo absorber to generate charge carriers and the organic polymers act as hole transport materials (HTM) [12], CIGS (Copper, Indium, Gallium, Selenium) on Mo back contact layer followed by a very thin CdS buffer layer and $\mathrm{ZnO}$ window layer (Fig. 1) [13], and dense polycrystalline $\mathrm{CuInSe}_{2}$ semiconductor thin film from printed precursors by thermal treatment at ambient selenium atmosphere ie selenization [14].

\section{Selenium in quantum dot solar cell}

\subsection{Mechanism}

In quantum dot (QD) based solar cells, light ray enters through the transparent electrode and strikes the quantum dot particles, which raises the energy of some of the electrons in the quantum dots. These excited electrons get injected into the titanium dioxide layer and travels through it up to the conducting surface of the electrode. Simultaneously the holes left behind in the quantum dot gets filled by electrons from the electrolyte, which in turn is taken from the counter electrode. This process creates a voltage across the cell and induces a current.

\subsection{Advantages}

Quantum dot captures excess photon energy which is usually wasted in a conventional solar cell. This is because semiconductors have a single band gap and hence absorb sunlight at a particular wavelength, whereas the bang gap of a quantum dot can be tuned by changing the size and shape of the quantum dot by varying fusion duration or temperature. Therefore, QD based solar cells can absorb light not only in the visible region but also in the infrared region, accounting for half of the solar energy reaching the earth that remains inaccessible by other type of solar cells. Other plus points of QD solar cells are favorable power to weight ratio with high efficiency, mass and area savings leading to miniaturization, low production cost, and versatile use (not just rooftops).

\subsection{Limitations}

Cadmium selenide-based quantum dot solar cells are highly toxic in nature. Moreover, the quantum dots can have surface defects, which can influence the recombination of electrons and holes by creating a temporary trap, thus giving rise to blinking quantum dots and deteriorating the quantum yield of the cell and require a very stable polymer shell. Having a stable polymer shell around the core can eliminate the blinking effect, but the shells can alter size selection and optical properties of the QD.

\subsection{Role and benefits of selenium}

Selenium based quantum dots (QD) can be used in two different types of solar cells: In Schottky solar cells [15] and in QD-sensitized solar cells. Furthermore, the selenium based QDs can sensitize the solar cell in monolayer form [16] or multilayer form [17] or by modifying the electrolyte [18].

Schottky junction is formed between a semiconductor and a metal, due to the induced depletion or inversion layer in the semiconductor. The associated potential is called Schottky barrier. Reports [15] show that Schottky solar cells using $\mathrm{PbS} \mathrm{QD}$ or $\mathrm{PbSe} \mathrm{QD}$ can generate a power conversion efficiency (PCE) of 1.8-2.1\% under AM1.5G illumination. Here the PbSe QDs films exhibit p-type semiconductor behavior after thiol treatment and form Schottky junctions on contact with metals. Although the short circuit current densities $\left(J_{\mathrm{sc}}\right)$ are quite high, the open circuit voltage $\left(V_{\mathrm{oc}}\right)$ of $\mathrm{PbS}$ or PbSe Schottky solar cells can be manipulated by changing the metal contacts. For example the low $\left(V_{\mathrm{oc}}\right)$ value of $0.05 \mathrm{~V}$ due to high work function of Au can be increased to $0.2-0.3 \mathrm{~V}$ by replacing $\mathrm{Au}$ contact with Al-coated $\mathrm{Ca}$ or $\mathrm{Mg}$ metal 
contact [19] and further increased to $0.51 \mathrm{~V}$ by introducing $\mathrm{Al} / \mathrm{LiF}$ contact, [20].

Near infrared (NIR)-absorbing copper-indium-selenide (CISe) QD-sensitized solar cell has been reported in literature [16], with optimized light absorption and electron injection capability to $\mathrm{TiO}_{2}$ conduction band, giving rise to a conversion efficiency of $4.3 \%$ under AM1.5G one sun illumination (Table 1, Fig. 2), yet being completely devoid of toxic heavy metals like cadmium and lead found in conventional QD solar cells. This optimization corresponds to the CISe QD size of $4 \mathrm{~nm}$ and active area of $0.39 \mathrm{~cm}^{2}$.

An optimized efficiency of $4.94 \%$ has been reported in literature [17] where $\mathrm{ZnSe}(10), \mathrm{CdS}(5)$ and $\mathrm{CdSe}(6)$ QDs were sequentially assembled on a nanocrystalline $\mathrm{TiO}_{2}$ film using SILAR process (successive ionic layer adsorption and reaction), where the numbers in the parenthesis indicate the cycles of immersion each with a dipping time of $2 \mathrm{~min}$. The performance of this multi-layered QDsensitized solar cell was found to be strongly dependent on the order of the QDs with respect to $\mathrm{TiO}_{2}$. Here ZnSe QD layer acted as a seed layer, inducing both the nucleation and growth of CdS QDs, whereas CdS and CdSe QDs had a complementary effect in light harvesting.

Another interesting approach is to modify the electrolyte with some additive to improve the performance of QD solar cells. It has recently been reported [18] that adding elemental selenium (Se) to polysulfide electrolyte to form polyselenosulfide species, not only inhibits the charge recombination at photoanode/electrolyte interface, but also reduces the charge transfer resistance at counter electrode/ electrolyte interface, resulting in improved $J_{\mathrm{sc}}$ and FF values (Tab. 1, Fig. 2) and a high efficiency of $9.78 \%$ in $\mathrm{Zn}-\mathrm{Cu}$-In-Se QD-sensitized solar cell.

\section{Selenium in dye-sensitized solar cells}

\subsection{Mechanism}

In dye sensitized solar cell (DSSC), a thin layer of titanium dioxide $\left(\mathrm{TiO}_{2}\right)$ is applied on Indium tin oxide (ITO) or fluorine doped tin oxide (FTO) substrate and semiconductor exhibits a high surface area because of its high porosity. The anode is soaked with a dye solution which bonds to the $\mathrm{TiO}_{2}$. The dye, also called photosensitizers, is mostly a ruthenium complex or various organic metal free compounds like blackberry or pomegranate juice. The cathode is a glass plate with a thin Pt film which serves as a catalyst [21]. An iodide/triiodide solution is used as the electrolyte. When light shines on the cell, dye molecules get excited from their ground state to a higher energy state. The excited dye molecule has now a higher energy content and overcomes the band gap of the semiconductor. The excited dye molecule is oxidized and an electron is injected into the conduction band of the semiconductor. Electrons are then transported to the current collector of the anode via diffusion process. The oxidized dye molecule is again regenerated by electron donation from the iodide in the electrolyte. In return, iodide is regenerated by reduction of triiodide on the cathode.

\subsection{Advantages}

Dye-sensitized solar cells (DSSCs) are more suitable in low density applications such as rooftop solar collectors, where the light weight and mechanical robustness of the printable cell play a key role. Another big advantage is that DSSCs work even in low-light conditions such as non-direct sunlight and cloudy skies. They are low cost, easy to manufacture, and constructed from abundant and

Table 1. Efficiency, open-circuit voltage, short-circuit current, and fill factor of various selenium containing solar cells categorized by cell types, a summary of literature review

\begin{tabular}{|c|c|c|c|c|c|c|}
\hline $\begin{array}{l}\text { Names and types of Se- } \\
\text { containing solar cells }\end{array}$ & $\begin{array}{l}\text { Efficiency } \\
\quad \eta(\%)\end{array}$ & $\begin{array}{c}\text { Open-circuit } \\
\text { voltage } \\
V_{\text {oc }}(\mathrm{V})\end{array}$ & $\begin{array}{c}\text { Short-circuit } \\
\text { current density } \\
J_{\mathrm{sc}}\left(\mathrm{mA} \cdot \mathrm{cm}^{-2}\right)\end{array}$ & $\begin{array}{l}\text { Fill factor } \\
\text { FF }(\%)\end{array}$ & $\begin{array}{c}\text { Year of } \\
\text { publication }\end{array}$ & References \\
\hline $\begin{array}{l}\text { AlGaInP multijunction with } \\
\text { Se emitter dopant }\end{array}$ & 10.7 & 1.54 & 7.9 & 88.0 & 2015 & {$[6]$} \\
\hline ITO/glass-Te-Se-Pt thin film & 2.5 & 0.5 & 10 & 50 & 1982 & {$[8]$} \\
\hline$n-\mathrm{TiO}_{2} / \mathrm{Se} / \mathrm{p}-\mathrm{CuCNS}$ thin film & 0.13 & - & 3 & - & 1998 & {$[11]$} \\
\hline $\begin{array}{l}\mathrm{TiO}_{2} / \mathrm{Se} / P_{3} \mathrm{HT} / \mathrm{PEDOT}: \mathrm{PSS} / \mathrm{Ag} \\
\text { thin film }\end{array}$ & 2.63 & 0.71 & 9.71 & 38.1 & 2014 & {$[12]$} \\
\hline$\overline{\mathrm{PbS}_{x} \mathrm{Se}_{1-x} \text { QD Schottky }}$ & 3.3 & 0.45 & 14.8 & 49.5 & 2010 & {$[20]$} \\
\hline CISe QD-sensitized & 4.3 & 0.56 & 14.48 & 53 & 2013 & {$[16]$} \\
\hline $\begin{array}{l}\text { Multi-layered - QD-sensitized } \\
\mathrm{ZnSe}(10) / \mathrm{CdS}(5) / \mathrm{CdSe}(6)\end{array}$ & 4.94 & 0.65 & 15.64 & 48.6 & 2015 & {$[17]$} \\
\hline $\begin{array}{l}\text { Se electrolyte additive in Zn- } \\
\mathrm{Cu} \text {-In-Se QD-sensitized }\end{array}$ & 9.78 & 0.60 & 26.24 & 62.1 & 2019 & {$[18]$} \\
\hline $\mathrm{SeS}_{2}$ : S: DIB dye-sensitized & 1.7 & 0.75 & 5.04 & 45 & 2017 & {$[22]$} \\
\hline $\begin{array}{l}\mathrm{BaZr}\left(\mathrm{S}_{0.6} \mathrm{Se}_{0.4}\right)_{3} \text { distorted } \\
\text { chalcogenide perovskite }\end{array}$ & 41.43 & 2.25 & 20.51 & 89.8 & 2020 & [29] \\
\hline
\end{tabular}




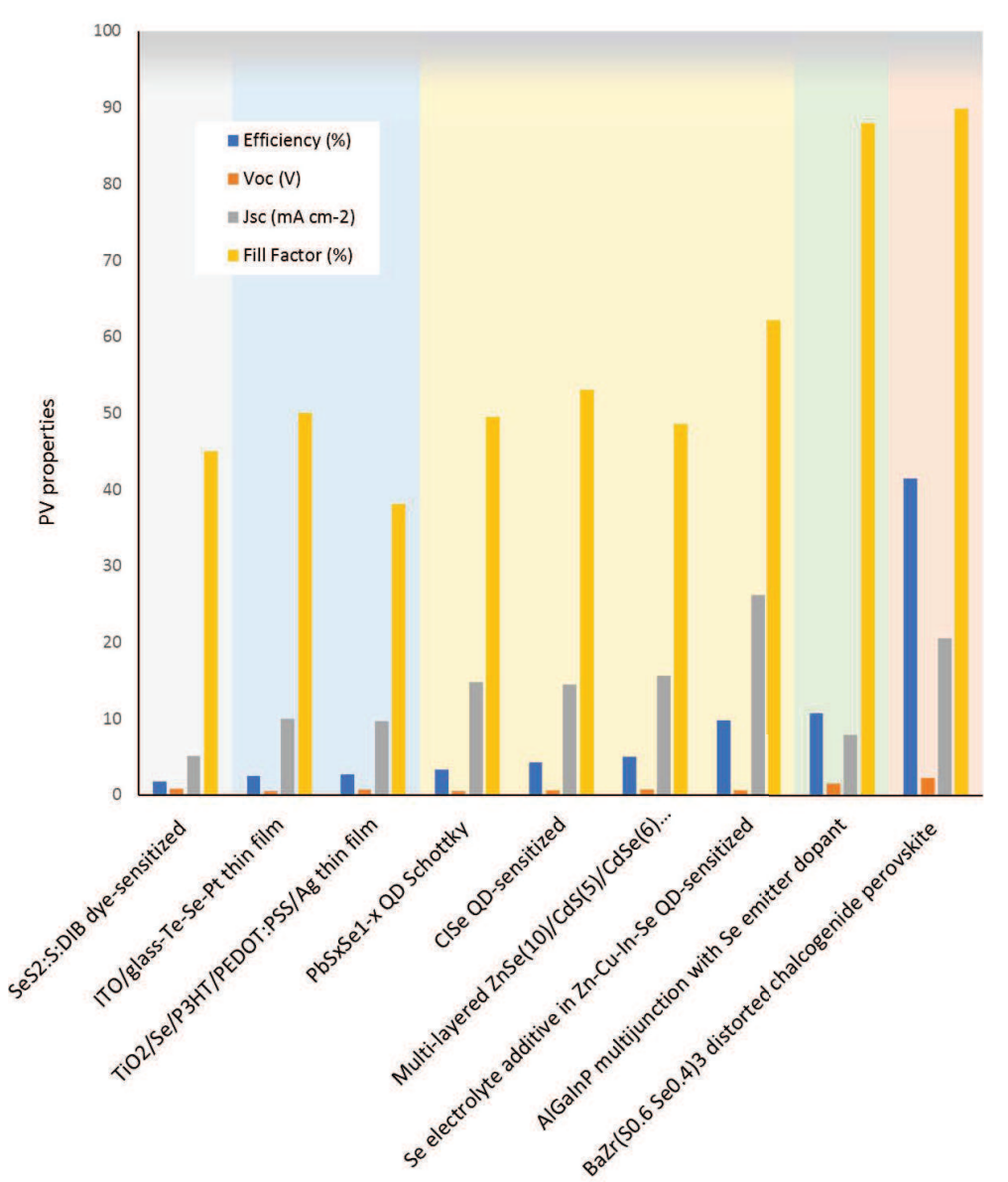

Fig. 2. Photovoltaic (PV) properties of different types of selenium containing solar cells as obtained from Table 1. Grey section: dye sensitized, blue section: thin film, yellow section: QD based, green section: multijunction, pink section: perovskite

stable resource materials. They offer higher power conversion efficiency than the silicon-based counterparts absorbing more sunlight per surface area.

\subsection{Limitations}

The electrolyte in DSSCs can freeze at low temperatures cutting off the power production and causing physical damage. Higher temperatures cause the liquid to expand, making sealing of the panels a difficult task. Another disadvantage is the high cost of ruthenium (dye), platinum (catalyst) and conducting glass or plastic (contact) that are needed to produce a DSSC.

\subsection{Role and benefits of Selenium}

Selenium-doped polymeric sulfur $\left(\mathrm{SeS}_{2}: \mathrm{S}: \mathrm{DIB}\right.$, where $\mathrm{DIB}=1.3$-diisopropenylbenzene) as hole- transporting material (HTM) can improve power conversion efficiency in both DSSC and perovskite solar cells. Under standard AM1.5G illumination, a power conversion efficiency of $1.7 \%$ (Tab. 1, Fig. 2) can be achieved due to selenium doping in cross-linked polymeric sulfur DSSC [22], which can be attributed to a reduction in band gap of the inorganic polymer (reflected in broader absorption peak due to Se-Se bonding) and an increased conductivity of $2.24 \times 10^{-4} \mathrm{~S} \cdot \mathrm{cm}^{-1}$ (3.5 times increase in comparison to pure sulfur polymer). The authors concluded that the poor Jsc and FF values are due to incomplete pore filling of the mesoporous $\mathrm{TiO}_{2}$ substrate.

\section{Selenium in perovskite solar cell}

\subsection{Mechanism}

Perovskites are a group of materials with cubic latticenested octahedral layered structures similar to the naturally occurring mineral calcium titanate $\left(\mathrm{CaTiO}_{3}\right)$ and is generally represented by the formula $\mathrm{ABX}_{3}$, where $\mathrm{A}$ and $\mathrm{B}$ are cations and $\mathrm{X}$ is halogen anion or oxide (Fig. 3). Chalcogenide perovskites are represented as $\mathrm{ABS}_{3}$, where $\mathrm{A}$ is an alkali earth metal eg $\mathrm{Ca}, \mathrm{Sr}$ or $\mathrm{Ba}, \mathrm{B}$ is an early transition metal eg $\mathrm{Ti}, \mathrm{Zr}$ or $\mathrm{Hf}$, and $\mathrm{S}$ is a group IV atom like sulfur (S) and selenium (Se). Perovskite material not only serve as a light-absorbing layer, but also as an electron/hole transport layer in solar cells. When exposed to sunlight, perovskite layer effectively absorbs photons to produce excitons (electron-hole pairs) due to their high extinction coefficient. These excitons can then form free carriers (free electrons and holes) to generate a current. The structure of perovskite material enables low carrier recombination probability, high charge mobility, long carrier lifetime, and long carrier diffusion distance, leading to 
superior performance in solar cells. For example, the carrier diffusion distance is around $100 \mathrm{~nm}$ for $\mathrm{CH}_{3} \mathrm{NH}_{3} \mathrm{PbI}_{3}$ and longer than $1 \mu \mathrm{m}$ for $\mathrm{X}=\mathrm{Cl}$, [23, 24]. Finally, the electrons are transferred from the perovskite material to $\mathrm{TiO}_{2}$ [25], which acts as the electron transport material (ETM) layer and collected by FTO (fluorine doped tin oxide) glass plate, while the holes are transferred to the hole transport material (HTM) layer and collected by the metal electrode. When FTO and metal electrode are connected, the photocurrent is generated in the outer circuit.

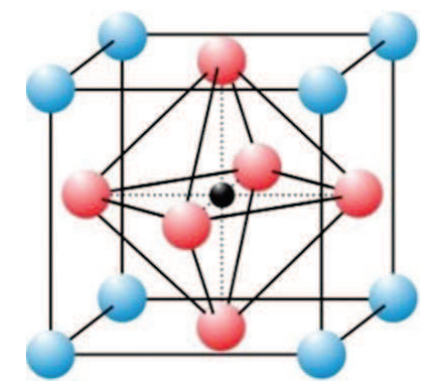

Fig. 3. Typical $\mathrm{ABX}_{3}$ perovskite structure showing cubic crystal with nested octahedron, where blue spheres are A cations, black spheres are B cations, and red spheres are $\mathrm{X}$ anions

\subsection{Advantages}

Perovskite solar cells can be manufactured using a simple solution deposition techniques such as spray coating and roll-to-roll printing that requires nominal cost. Perovskites are defect tolerant, which means that competitive device efficiency can be achieved without the need of purity that a silicon solar cell demands. Perovskite solar cells can show extreme flexibility in terms of crystal structure and composition [26]. A large number of different elements can be combined together to form perovskite structure with varied group symmetry, allowing scientists to optimize the physical, optical, aesthetic, and electrical properties of perovskite solar cells.

\subsection{Limitations}

One major challenge in commercializing halide perovskite solar cells is protecting the cells from moisture, a factor that can significantly lower their performance outdoors. Hybrid perovskites are intrinsically unstable, showing rapid phase transformation under light illumination and heat/air exposure. Polymeric coatings may solve this problem but may bring in more complexities. Moreover, the presence of toxic lead atoms in hybrid halide perovskites is quite undesirable for large-area applications.

\subsection{Role and benefits of selenium}

Chalcogenide perovskites are considered as promising candidates for overcoming the stability and toxic issues of halide perovskites. First-principle calculations show that the prototype cubic phase of chalcogenide perovskite exhibits indirect band gap with the valence band maximum and the conduction band minimum located in the Brillion zone [27]. Therefore, the optical transition near band edges of chalcogenide perovskite differs from those of its halide counterpart, although its stable orthorhombic phase embodies a direct band gap [27]. The predicted band gaps of $\mathrm{CaTiS}_{3}, \mathrm{BaZrS}_{3}, \mathrm{CaZrSe}_{3}$, $\mathrm{CaHfSe}_{3}, \mathrm{BaZrSe}_{3} \mathrm{SrZrSe}_{3}, \mathrm{BaHfSe}_{3}$ and $\mathrm{SrHfSe}_{3}$ with the distorted chalcogenide perovskite structure are within the optimal range for making single-junction solar cells $[26,28]$ and appear to be promising candidates for solar cells. The predicted optical absorption properties of these materials are also superior compared to other highefficiency solar-cell materials and replacement of alkalineearth cations by molecular cations eg $\mathrm{CH}_{3} \mathrm{NH}_{3}^{2+}$ is also possible to obtain organic-inorganic hybrid cells.

Recent research [29] shows that the distorted chalcogenide perovskites are experimentally found to exhibit extra-ordinarily high $\alpha$ exceeding $10^{5} \mathrm{~cm}^{-1}$ near $E_{g}$, unveiling the highest band-edge among all known solar cell materials. The $E_{g}$ value of $\mathrm{BaZrS}_{3}$-based alloys eg $\mathrm{BaZr}\left(\mathrm{S}_{0.6} \mathrm{Se}_{0.4}\right)_{3}$ was found to be $1.76 \mathrm{eV}$ corresponding to a theoretical conversion efficiency of $41.4 \%$ (Tab.1, Fig. 2) at $2 \mu \mathrm{m}$ [28], indicating that alloying of $\mathrm{BaZrS}_{3}$ with Se lowers $E_{g}$ effectively and the light absorption range extends toward lower energies. The strong tail absorption in such chalcogenide alloy can be attributed to the intense atom clustering due to limited solubility of S-Se and presence of $\mathrm{Ba}_{3} \mathrm{Zr}_{2} \mathrm{~S}_{7}$ secondary phase [29].

\section{Major players and cost analysis}

Solar cell industry has come a long way since Gratzel's invention of DSSC solar cells in Switzerland followed by brand leadership of 3GSolar Photovoltaics, the pioneering work on perovskite solar cells by Tsutomu Miyasaka in Japan and subsequent commercialization by Oxford $\mathrm{PV}$ in the UK, Nanosolar's designing, engineering and manufacturing of innovative thin film solar cells and panels including printed CIGS, not to speak of traditional monocrystalline silicon solar cells. Solar cells market is currently dominated by Chinese manufacturers like Jinko Solar, JA Solar, Tongwei and Trina Solar. Sunpower and Panasonic manufacture solar panels with some of the lowest temperature coefficients available in the industry, which is particularly well suited for hot climates.

Double sided bifacial solar cells are gaining popularity, as the panels can sit vertically on land or rooftops soaking up the best of solar energy. Table 2 shows a comparative cost analysis of different kinds of solar cells. There are effective non-toxic ways of glass surface cleaning, which only adds up a little to the solar panel cost [30]. Surface thermodynamic parameters [31] especially the free energy for charge transfer at the interface $(\Delta G)$ plays a vital role in determining the limiting efficiency of excitonic solar cells. The $-\Delta G$ value typically in the range 0.3 to 0.5 $\mathrm{eV}$ can decrease the maximum efficiency to $27 \%$ and $22 \%$ 
Table 2. Costs and life spans of different solar cells as obtained from literature

\begin{tabular}{lccc}
\hline Major types of solar cells & Cost per Watt (USD) & Life span (years) & Source references \\
\hline Traditional silicon crystalline & $0.65-0.75$ & 25 & Nextbigfuture.com, [34] \\
Copper indium gallium selenide thin film & 0.61 & 12 & {$[34]$} \\
Gallium arsenide thin film & 0.39 & 18 & {$[34]$} \\
Cadmium telluride thin film & 0.53 & 20 & {$[34]$} \\
Amorphous silicon thin film & 0.54 & 15 & {$[34]$} \\
PbS quantum dot & $0.24-0.93$ & & {$[35]$} \\
CsPbI 3 perovskite quantum dot & 0.83 & & {$[35]$} \\
Dye sensitized & 2.50 & 30 & Thefutureofthings.com \\
Bifacial & 0.15 & 20 & {$[34]$} \\
Perovskite & 0.13 & & {$[34]$} \\
\hline
\end{tabular}

respectively [32] from the theoretical $31 \%$ based on second law of thermodynamics [33].

\section{Conclusion}

From this literature review, it is quite apparent that selenium can play a significant role in different types of solar cells. As far as PV properties are concerned, $\operatorname{BaZr}\left(\mathrm{S}_{0.6} \mathrm{Se}_{0.4}\right)_{3}$ distorted chalcogenide perovskite solar cell can possibly lead the future, the next best ones being AlGaInP multijunction solar cell with Se emitter dopant and Se electrolyte additive in $\mathrm{Zn}-\mathrm{Cu}$-In-Se QD-sensitized solar cell. Cost-wise perovskite cells look appealing as well, but the efficacy of selenium needs to be explored further.

\section{REFERENCES}

[1] T. K. Teodor, S. Singh, D. M. Bishop, O. Gunawan, Y. S. Lee, T. S. Gershon, K. W. Brew, P. D. Antunez, and R. Haight, "Ultrathin high band gap solar cells with improved efficiencies from the worlds oldest photovoltaic material", Nat. Commun., vol. 8, no. 1, pp. 682, Sep. 2017, doi: 10.1038/s41467-017- 00582-9.

[2] S. Almosni et al, "Material challenges for solar cells in the twenty-first century: directions in emerging technologies", Sci. Technol. Adv. Mater.,, vol. 19, no. 1, pp. 336-369., Apr. 2018, doi: 10.1080/14686996.2018.1433439.

[3] P. Colter, B. Hagar, and S. Bedair, "Tunnel Junctions for III-V Multijunction Solar Cells Review" Crystals, vol. 8, no. 12, pp. 445-459, Nov. 2018, doi: 10.3390/cryst8120445.

[4] M. Ochoa, E. Barrigon, L. Barrutia, I. Garcia, I. Rey-Stolle, and C. Algora, "Limiting factors on the semiconductor structure of III-V multijunction solar cells for ultra-high concentration (1000-5000 suns): Limiting factors of multijunction solar cells for ultra-high concentration", Prog. Photovolt., vol. 24, no. 10, pp. 1332-1345, Jun. 2016, doi: 10.1002/pip.2791.

[5] G. A. Landis, "Selenium interlayer for high-efficiency multijunction solar cell", US patent US9418844B1, Aug. 16, 2016.

[6] E. E. Perl, J. Simon, J. F. Geisz, W. Olavarria, M. Young, A. Duda, P. Dippo, D. J. Friedman, and M. A. Steiner (2015), "Development of a $2.0 \mathrm{eV}$ AlGaInP Solar Cell Grown by OMVPE", Presented at IEEE 42nd Photovoltaic Specialist Conference (PVSC), New Orleans, LA, USA, Jun. 14-19, 2015.
[7] T. Dey, "Magnetic nanoparticles and cellulosic nanofibers to remove arsenic and other heavy metals from water", Nanotechnology for water purification (Ed) T. Dey, Boca Raton, USA: Universal Publishers, 2012, pp. 1-28.

[8] A. Kunioka and T. Nakada, "High-efficiency selenium photovoltaic solar cells", Jpn. J. Appl. Phys., vol. 21, no. S2, pp. 73-75, 1982.

[9] T. Dey and D. Naughton, "Nano-porous sol-gel derived hydrophobic glass coating for increased light transmittance through greenhouse", Mater. Res. Bull., vol. 116, pp. 126-130, Aug. 2019, doi: 10.1016/j.materresbull.2019.04.027.

10] T. Nakada and A. Kunioka, "Polycrystalline thin-film $\mathrm{TiO}_{2} / \mathrm{Se}$ solar cells", Jpn. J. Appl. Phys., vol. 24, no. 7A, pp. L536-L538, 1985.

[11] K. Tennakone, G. R. R. A. Kumara, I. R. M. Kottegoda, V. P. S. Perera, and G. M. L. P. Aponsu, "Nanoporous n- $\mathrm{TiO}_{2}$ / selenium/ p-CuCNS photovoltaic cell", J. Phys. D: Appl. Phys., vol. 31, no. 18 , pp. $2326-2330$, June 1998, doi: 10.1088/0022-3727/31/18 $/ 019$.

[12] K. Wang, Y. Shi, H. Zhang, Y. Xing, Q. Dong, and T. Ma, "Selenium as photoabsorber for inorganic- organic hybrid solar cells", Phys. Chem. Chem. Phys., vol. 16, no. 42, pp. 23316-23319, Nov. 2014, doi: 10.1039/c4cp02821j.

[13] Y. Tang, "Copper indium gallium selenide thin film solar cells", Nanostructured solar cells, (Ed) N. Das, InTech Open, 2017, doi: $10.5772 / 65291$.

[14] A. E. Zaghi, M. Buffiere, J. Koo, G. Brammertz, M. Batuk, C. Verbist, J. Hadermann, W. K. Kim, M. Meuris, J. Poortmans, and J. Vleugels, "Effect of selenium content of $\mathrm{CuInSe}_{x}$ alloy nanopowder precursors on recrystallization of printed $\mathrm{CuInSe}_{2}$ absorber layers during selenization heat treatment", IThin Solid Films, vol. 582, pp. 11-17, May 2015, doi: 10.1016/j.tsf.2014.10 .003 .

[15] L. Etgar, "Semiconductor nanocrystals as light harvesters in solar cells", Materials, vol. 6, no. 2, pp. 445-459, Feb. 2013, doi: $10.3390 /$ ma6020445.

[16] J. Yang, J-Y Kim, J. H. Yu, T-Y Ahn, H. Lee, T-S Choi, Y-W Kim, J. Joo, M. J. Ko, and T. Hyeon, "Copper-indium-selenide quantum dot-sensitized solar cells", Phys. Chem. Chem. Phys., vol. 15 , no. 47 , pp. 20517-20525, Nov. 2013, doi: 10.1039/c3cp $54270 \mathrm{j}$.

[17] L. Yang, C. McCue, Q. Zhang, E. Uchaker, Y. Mai, and G. Cao, "Highly efficient quantum dot- sensitized $\mathrm{TiO}_{2}$ solar cells based on multilayered semiconductors (ZnSe/CdS/CdSe)", Nanoscale, vol. 7, no. 7, pp. 3173-3180, Dec. 2014, doi: 10.1039/C4NR06935H

[18] M. Zhou, G. Shen, Z. Pan, and X. Zhong, "Selenium cooperated polysulfide electrolyte for efficiency enhancement of quantum 
dot-sensitized solar cells", J. Energy Chem., vol. 38, pp. 147-152, Nov. 2019, doi: 10.1016/j.jechem.2018.12.010.

[19] K. W. Jonhston, A. G. Pattantyus-Abraham, J. P. Clifford, S. H. Myrskog, D. D. MacNeil, L. Levina, and E. H. Sargent "Schottky-quantum dot photovoltaics for efficient infrared power conversion" Appl. Phys. Lett. vol. 92, no. 15, pp. 151115:1-151115:3, Apr. 2008, doi: 10.1063/1.2912340.

[20] D. Ratan, T. Jiang, D. A. Barkhouse, W. Xihua, G. P-A Andras, B. Lukasz, L. Larissa, and E. H. Sargent, "Ambient-processed colloidal quantum dot solar cells via individual pre-encapsulation of nanoparticles", J. Am. Chem. Soc.,, vol. 132, no. 17, pp. 5952-5953, Apr. 2010, doi: 10.1021/ja1013695

[21] O. P. Yadav, Y. K. Yadav, A. R. Das, T. Dey, S. Kakkar, and M. L. Singla, "Catalytic oxidation of carbonmonoxide using platinum nanoparticles synthesized in microemulsion", Asian J. Sci. Res.,, vol. 1, no. 1, pp. 79-84, 2008, doi: 10.3923/ajsr.2008.79.84.

[22] P. Liu, L. Kloo, and J. M. Gardner, "Cross-linked sulfur-selenium polymers as hole-transporting materials in dye-sensitized solar cells and perovskite solar cells", ChemPhotoChem, vol. 1, no. 8, pp. 363- 368, Aug. 2017, doi: 10.1002/cptc.201700037.

[23] M. A. Green, A. Ho-Baillie, and H. J. Snaith, "The emergence of perovskite solar cells", Nat. Photonics, vol. 8, no. 7, pp. 506-514, Jul. 2014, doi: 10.1038/NPHOTON.2014.134.

[24] S. P. Singh and P. Nagarjuna, "Organometal halide perovskites as useful materials in sensitized solar cells", Dalton Trans.,, vol. 43, no. 14, pp. 5247-5251, Feb. 2014, doi: 10.1039/c3dt53503g.

[25] T. Dey, "UV-reflecting sintered nano- $\mathrm{TiO}_{2}$ thin film on glass for anti-bird strike application", Surf. Eng., July 2020, doi: 10.1080/02670844.2020.1796900.

[26] Z. Huo, S-H Wei, and W-J Yin, "High-throughput screening of chalcogenide single perovskites by first-principles calculations for photovoltaics", J. Phys. D Appl. Phys., vol. 51, no. 47, Art no. 474003, Sep. 2018, doi: 10.1088/1361-6463/aae1ee.

[27] Y. Peng, Q. Sun, H. Chen, and W-J Yin, "Disparity of the Nature of the Band Gap between Halide and Chalcogenide Single Perovskites for Solar Cell Absorbers", J. Phys. Chem. Lett., vol. 10, no. 16, pp. 4566- 4570, Aug. 2019, doi: 10.1021/ acs.jpclett.9b01657.

[28] Y. Y. Sun, M. L. Agiorgousis, P. Zhang, and S. Zhang, "Chalcogenide Perovskites for Photovoltaics", Nano Lett., vol. 15, no. 1, pp. 581-585, Jan. 2015, doi: 10.1021/nl504046x.

[29] Y. Nishigaki, T. Nagai, M. Nishiwaki, T. Aizawa, M. Kozawa, K. Hanzawa, Y. Kato, H. Sai, H. Hiramatsu, H. Hosono and H. Fujiwara, "Extraordinary Strong Band-Edge Absorption in Distorted Chalcogenide Perovskites", Sol. RRL, vol. 4, no. 5, Art no. 1900555, Jan. 2020, doi: 10.1002/solr.201900555.

[30] T. Dey and D. Naughton, "Cheap non-toxic non-corrosive method of glass cleaning evaluated by contact angle, AFM, and
SEM-EDX measurements", Environ. Sci. Pollut. Res., vol. 24, no. 15, pp. 13373- 13383, May. 2017, doi: 10.1007/s11356-017 $-8926-4$.

31] A. Chatterjee, T. Dey, S. K. Sanyal, and S. P. Moulik, "Thermodynamics of micelle formation and surface chemical behaviour of p-tert-octylphenoxypolyethylene ether (Triton X-100) in aqueous medium", J. Surface Sci. Technol., vol. 17, no. 1-2, pp. 1-15, 2001

32] N. C. Giebink, G. P. Wiederrecht, M. R. Wasielewski, and S. R. Forrest, "Thermodynamic efficiency limit of excitonic solar cells", Phys. Rev. B, vol. 83, no. 19, Art no. 195326, May 2011, doi: 10.1103/PhysRevB.83.195326.

33] W. Shockley and H. J. Queisser, "Detailed Balance Limit of Efficiency of p-n Junction Solar Cells", J. Appl. Phys.,, vol. 32, no. 3, pp. 510-519, 1961, doi: 10.1063/1.1736034.

[34] R. V. Angadi, B. Revanasiddesh, and P. K. Vineet Kumar, "A review on different types of materials employed in solar photovoltaic panel", Int. J. Eng. Res. Technol., vol. 7, no. 8, Art no IJERTCONV7IS08084, 2019.

35] J. Jean, J. Xiao, R. Nick, N. Moody, M. Nasilowski, M. Bawendi, and V. Bulović, "Synthesis cost dictates the commercial viability of lead sulfide and perovskite quantum dot photovoltaics", Energy Environ. Sci., vol. 11, no. 9, pp. 2295-2305, Jul. 2018, doi: 10.1039/C8EE01348A.

Received 22 March 2021

Tania Dey (PhD), was born in India on 1973, obtained her doctorate degree in chemistry in 2002 and since then has spent her entire post-PhD work life in North America and Europe. She is a senior scientist and chemical consultant by profession. Her research expertise encompasses various interdisciplinary areas in surface, polymers, ceramics and nanomaterials for diverse applications, with a strong focus on environment and sustainability ( $\mathrm{H}$ index 10, ORCID 0000-00034292-3383). She was awarded Marquis Who's Who in America in 2009 for her research accomplishments. She has served as an associate editor in a couple of journals, regularly acts as a peer-reviewer for several scientific journals and research grant reviewer for federal organizations. She is the author and editor of the book 'Nanotechnology for Water Purification' published in 2012. She has secured two research grant awards as a principal investigator in 2018. She is actively engaged in project leadership, cutting-edge research, publications, self-initiated collaboration, industrial consultancy and student supervision. 